\title{
Analysis of Contact Phenomena and Heat Exchange in the Cutting Zone Under Minimum Quantity Cooling Lubrication conditions
}

\author{
Radoslaw W. Maruda ${ }^{1}$ - Eugene Feldshtein ${ }^{1}$ - Stanislaw Legutko ${ }^{2}$ • \\ Grzegorz M. Krolczyk ${ }^{3}$
}

Received: 14 January 2015 / Accepted: 8 June 2015 / Published online: 20 June 2015

(C) The Author(s) 2015. This article is published with open access at Springerlink.com

\begin{abstract}
The paper critically investigates about the influence of emulsion mist cooling on the conditions of heat absorption from the machining zone. The cooling conditions under which the total number of drops falling on the hot surfaces of the machining zone evaporate have been studied. The state of cutting wedges made of P25 sintered carbide after finish turning of two-phase pearlite-ferrite AISI 1045 steel with the presence of an anti-seizure and anti-wear additive has been subjected to scanning inspection. In the contact area, the content of surface active compounds is much larger as compared to the areas beyond the contact. It has been observed that the concentration of active compounds on the surface grows by about three times. This phenomena provides confirmatory evidences of favourable machining conditions.
\end{abstract}

Keywords MQCL - Turning - Sustainability manufacturing · Scanning electron microscopy (SEM) • Thermally activated processes

Grzegorz M. Krolczyk

g.krolczyk@po.opole.pl

1 Faculty of Mechanical Engineering, University of Zielona Gora, 4 Prof. Z. Szafrana street, 65-516 Zielona Gora, Poland

2 Faculty of Mechanical Engineering and Management, Poznan University of Technology, 3 Piotrowo street, 60-965 Poznan, Poland

3 Faculty of Production Engineering and Logistics, Opole University of Technology, 76 Proszkowska street, 45-758 Opole, Poland

\section{List of symbols}

MQCL Minimum quantity cooling lubrication

MQL Minimum quantity lubrication

EP Extreme pressure

AW Anti-wear

$\kappa_{r} \quad$ Tool major cutting edge angle $\left({ }^{\circ}\right)$

$\kappa_{r}^{\prime} \quad$ Tool minor cutting edge angle $\left({ }^{\circ}\right)$

$\gamma \quad$ Rake angle $\left(^{\circ}\right)$

$\alpha_{0} \quad$ Clearance angle $\left(^{\circ}\right)$

$r_{\varepsilon} \quad$ Corner radius $(\mathrm{mm})$

AISI American Iron and Steel Institute

$R_{e H \text { min }} \quad$ Yield point $(\mathrm{MPa})$

$R_{m} \quad$ Tensile strength (MPa)

A5 Ultimate longitudinal elongation

HB Brinell hardness

$a_{p} \quad$ Depth of cut (mm)

$f \quad$ Feed rate $(\mathrm{mm} / \mathrm{rev})$

$v_{c} \quad$ Cutting speed $(\mathrm{m} / \mathrm{min})$

$P \quad$ Air flow volume $\left(\mathrm{m}^{3 /} \mathrm{h}\right)$

E Mass flow of emulsion (g/min)

$L \quad$ Nozzle distance from the machining zone (m)

$D \quad$ Drop diameter on the contact surface $(\mu \mathrm{m})$

$d \quad$ Drop diameter in air $(\mu \mathrm{m})$

$t_{1} \quad$ Drop heating time (s)

$t_{2} \quad$ Drop evaporation time (s)

$\alpha \quad$ Heat diffusivity coefficient $\left(\mathrm{W} / \mathrm{m}^{2} \mathrm{~K}\right)$

$c_{p} \quad$ Volumetric specific heat of water $(\mathrm{J} / \mathrm{kg} \mathrm{K})$

$\Theta_{0} \quad$ Medium temperature at the nozzle outlet $(\mathrm{K})$

$\Theta_{\mathrm{n}} \quad$ Drop saturation temperature (K)

$V_{\text {droplet }} \quad$ Drop volume in $\operatorname{air}\left(\mu \mathrm{m}^{3}\right)$

$N \quad$ Number droplets (pcs $/ \mathrm{mm}^{2}$ )

$A_{\text {surf } \quad \text { Wetting area (\%) }}$

$r \quad$ Water evaporation heat $(\mathrm{J} / \mathrm{kg})$

$\Theta_{S} \quad$ Heated surface temperature (K)

$\rho \quad$ Water density $\left(\mathrm{kg} / \mathrm{m}^{3}\right)$ 


\section{Introduction}

In those particular cases where dry machining is extremely difficult, the methods called Minimum Quantity Cooling Lubrication, MQCL, or Minimum Quantity Lubrication, MQL, are preferable options. In those methods, quasi-dry machining is effected, i.e. the quantity of the cooling and lubricating agent is lower than $100 \mathrm{ml} / \mathrm{h} \mathrm{[1]}$. The agent is delivered to the cutting zone by means of a stream of compressed air from outside or through the channels in the tool body. When the MQL and MQCL methods are applied, machining is not completely dry, and at the same time, the economical and environmental aspects become more favourable [2-4]. Such small quantities of the active medium suffice to significantly reduce friction on the surfaces of the cutting wedge, to prevent formation of adhesive joints and to absorb heat from the cutting zone $[5,6]$.

In the MQL method, the active components are synthetic or natural oils with cooling properties (heat capacity) much lower than water-based emulsion. The most important function of oils in the MQL method is the reduction in friction between the contacting surfaces of the wedge, the chip and the object being machined. That is why the most important purpose of the MQL method is to ensure appropriate supply of oil to the cutting zone [7]. A particularly important thing, in this case, is the diameter of the drops and their spatial location depending on the distance of the nozzle from the cutting zone. The air pressure of the smaller drops can ensure better penetration into the cutting zone, i.e. they are more favourable [8].

In order to compensate for the low cooling ability of the MQL method, water-based emulsion has been used to absorb more heat from the machining process due to better cooling conditions (MQCL method) [9]. The MQCL method has been seldom applied so far, and it is not critically investigated to a large extent. However, even marginal improvement in the cooling conditions can contribute to a large extent to the phenomena of heat exchange during machining. A minimum presence of emulsion in the machining zone influences the tribological aspects of the wedge/machined material interaction augmenting the efficacy of the lubrication. This happens due to the additions of various kinds of oils, soaps, extreme pressure, as well as other typical lubricating agents used during machining.

The above-mentioned modern methods of cooling are becoming more and more popular in industry because they have some striking advantages and, among others. They specifically manifest:

(1) reduction in costs involved in the use of coolinglubricating agents $[4,10-12]$;

(2) manufacturing parts with very close tolerances and superior surface finish [5,13-16];
(3) significant reduction of the cutting forces and, consequently, extension of tool life $[5,13,14,17]$;

(4) assurance of environment friendly production conditions (ecologically pure-sustainable manufacturing) $[4,18,19]$;

(5) appreciable reduction in the health hazards of the operators due to their continuous exposure to the cutting fluids $[4,9,18]$.

The aim of the work is to investigate and analyse the heat exchange phenomena in the MQCL method depending on the flow of active components, carrier medium pressure (compressed air), the diameter and number of drops contained in the emulsion mist as well as the effectiveness and efficacy of the delivery mechanism of the anti-wear additives in the cutting zone in the MQCL method.

\section{Materials and Methods}

The material under machining was AISI 1045 steel recommended by ISO 3685 as a model one. The chemical composition, structure and properties of the steel can be found in Table 1.

Based on industry recommendations, a range of cutting parameters was selected: $v_{c}=250 \mathrm{~m} / \mathrm{min}, f=0.3 \mathrm{~mm} / \mathrm{rev}$, $a_{p}=1 \mathrm{~mm}$.

In the experimental investigation, emulsion concentrate, namely OPORTET RG-2, has been used as the active medium in the experimental investigation. It is a universal medium applied in turning, milling, threading and other common machining practices. The concentrate does not lose its efficacy for a long period and does not contain such compounds as nitrides, chlorine, formaldehydes. The amount of concentrate content in water was $4 \%$.

The tests have been carried out with the use of an anti-seizure and anti-wear additive to the emulsion mainly Metalon-M, with combined action. The additive is a mixture of hydrocarbon compounds of special chemical composition (containing such elements as phosphor, sulphur, fluorine). The application of this additive ensures the reduction in friction and wear of ferrous and non-ferrous metals, as well as the minimization of energy losses. Unlike the additives added into oil mediums, Metalon-M chemically reacts with the top layer of the object being machined forming a microscopic, monomolecular anti-wear layer. It is very often used in industrial conditions in machining liquids and exploitation fluids. The concentration of Metalon-M in water was $5 \%$, i.e $50 \mathrm{ml}$ per one litre.

The mixture was prepared using electromagnetic stirrer type ES21H. Emulsion concentrate was added to the water, and it was heated up to $60^{\circ} \mathrm{C}$. To this solution, $5 \%$ of EP/ AW 
Table 1 Chemical composition, structure and properties of AISI 1045 steel

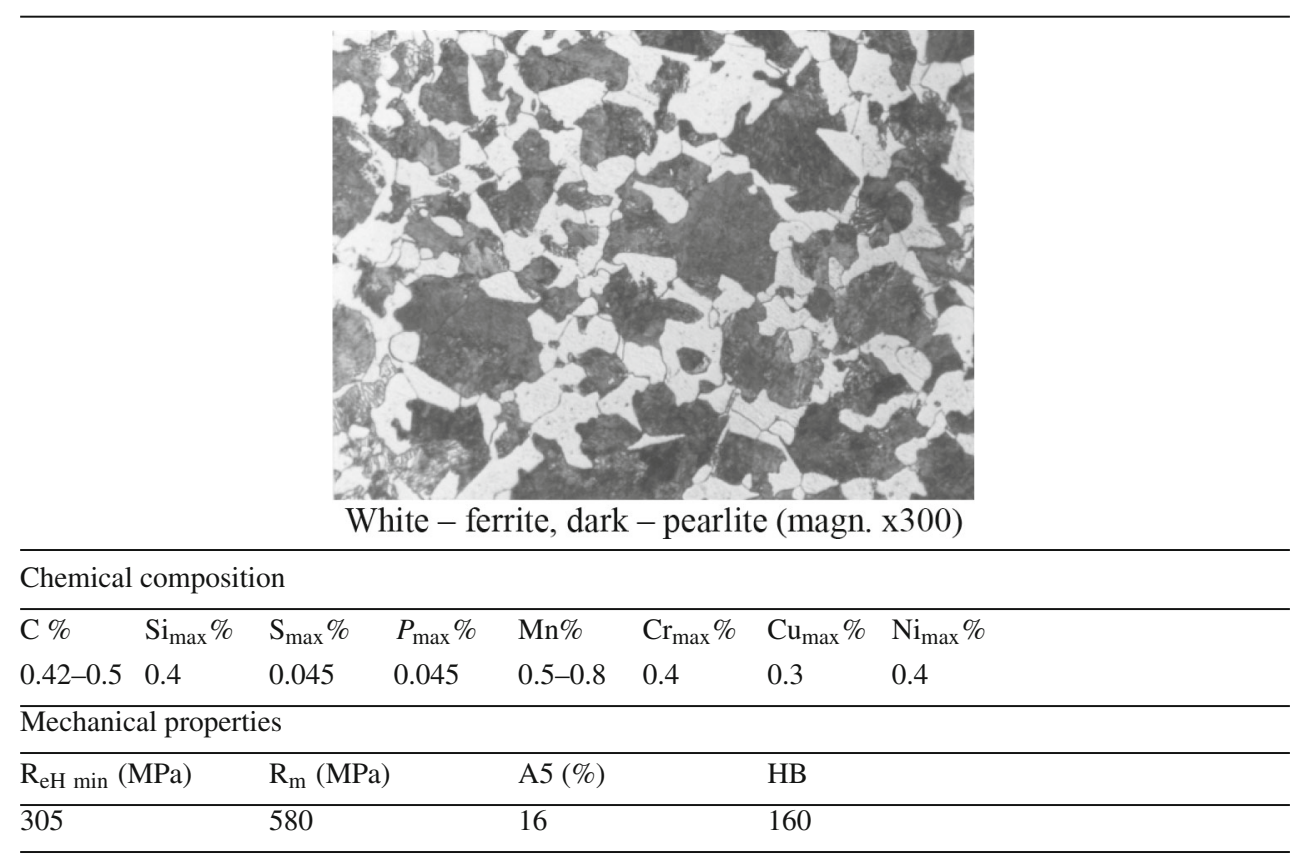

was added. Concentration by volume was selected according to prescribed guidelines from the manufacturers.

The tests were carried out on a CNC lathe, CTX310eco, in OUTech Surface Integrity Lab with the use of a cutting tool, with a CSDBM2020M12 holder and SNUN120408 changeable insert. Cutting wedge geometry: tool major cutting edge angle $\kappa_{r}=70^{\circ}$, tool minor cutting edge angle, $\kappa_{r}^{\prime}=20^{\circ}$, rake angle, $\gamma=-8^{\circ}$, clearance angle, $\alpha_{0}=8^{\circ}$, corner radius, $r_{\varepsilon}=0.8 \mathrm{~mm}$.

The emulsion mist has been made with the use of Micronizer 1LN Micro Unit Vlenox Nozzle provided with air and emulsion flow control. A schematic diagram of the experimental set-up is shown in Fig. 1.

A rotameter and precision scales have been used to determine: volumetric air flow, $P=4.7-6.9 \mathrm{~m}^{3} / \mathrm{h}$ and mass emulsion flow, $E=1.8-3.6 \mathrm{~g} / \mathrm{min}$. The compressed air pressure was $2 \mathrm{MPa}$. The distance between the nozzle and the contact zone of the cutting wedge with the material being machined was $0.4 \mathrm{~m}$ (based on industry recommendations). The research of the distribution of droplets has validated the choice of droplets within $0.4 \mathrm{~m}$. At this specific distance, it was observed that the highest number of droplets will evaporate within one second. A microscope has been utilized to determine the diameter of the drops and the number of drops falling on $1 \mathrm{~mm}^{2}$ of the surface. Utilizing the formula for the drop vaporization, the flows of forming emulsion mist have been established so that all the droplets evaporate in one second in the process of turning. Consequently, the scanning analysis of the cutting tool rake face has been performed by means of a JEOL JSM-5600LV scanning microscope. This inspection is to prove that the elements contained in the EP and AW additives remain on the rake face.

\section{Results and Discussion}

\subsection{Theoretical Analysis and Experimental Investigation of Heat Flow in the MQCL Method}

Table 2 shows the distributions of droplets falling per $1 \mathrm{~mm}^{2}$ (diameter and number) depending on the distance from the nozzle to the cutting zone for a constant volumetric flow and the mass of the emulsion. It was found that with increasing distance of the nozzle from the cutting interface reduces the total area of the wettability and the average diameter of the droplets on the surface. For the distance of $0.4 \mathrm{~m}$, the best value of diameters of the droplets is achieved and the largest number of droplets is obtained per unit $\mathrm{mm}^{2}$ area.

For the calculations, it has been assumed that the composition of the emulsion based on mineral oils consists of $96 \%$ water and $4 \%$ of concentrate. Thermal properties of the emulsion concentrate mainly depend on the oil as a component of largest mass and volume. The contents of the other ingredients are e.g. soap, corrosion inhibitors, etc., and their properties have not been investigated.

In the MQCL method, the heat transferring to a drop first elevates the temperature to the saturation level, $\Theta_{n}$, and then causes its vaporization. For the first part of the process, the thermal balance equation is as follows [20]:

$$
\frac{\pi D^{2}}{4} \alpha\left(\Theta_{n}-\Theta_{0}\right) t_{1}=c_{p} \frac{\pi d^{3}}{6}\left(\Theta_{n}-\Theta_{0}\right),
$$

where: $t_{1}$-heating time; $\alpha$-heat diffusivity coefficient; $c_{p}$-volumetric specific heat of water; $\Theta_{0}$ - medium temperature at the nozzle outlet; $D$-drop diameter on the contact surface; $d$-drop diameter in air. 


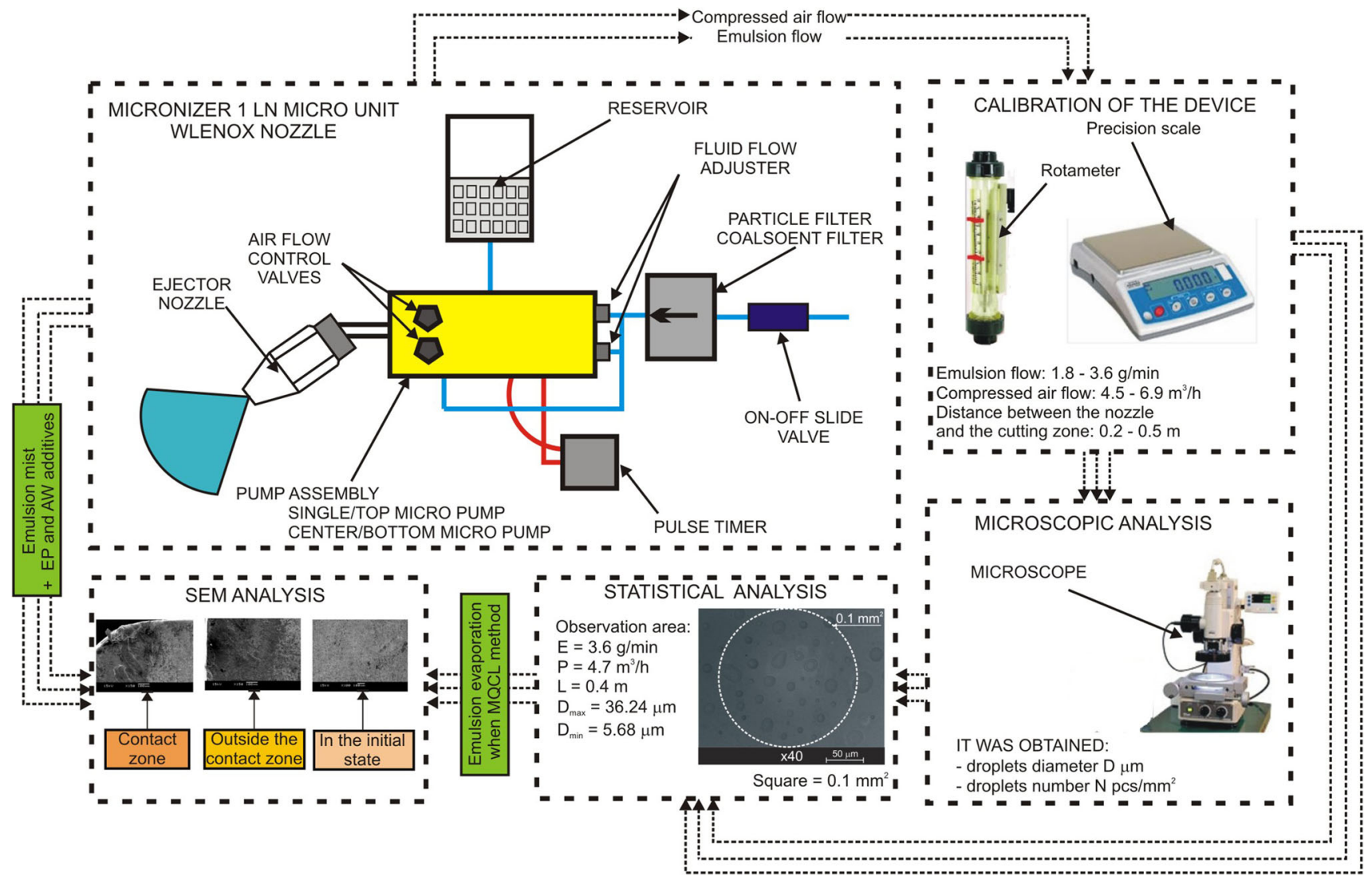

Fig. 1 A schematic diagram of the experimental set-up

Table 2 The changes in diameters and the number of droplets depending on the distance from the nozzle to the cutting zone $(E=3.6 \mathrm{~g} / \mathrm{min}$ and $P=4.7 \mathrm{~m}^{3} / \mathrm{h}$ )

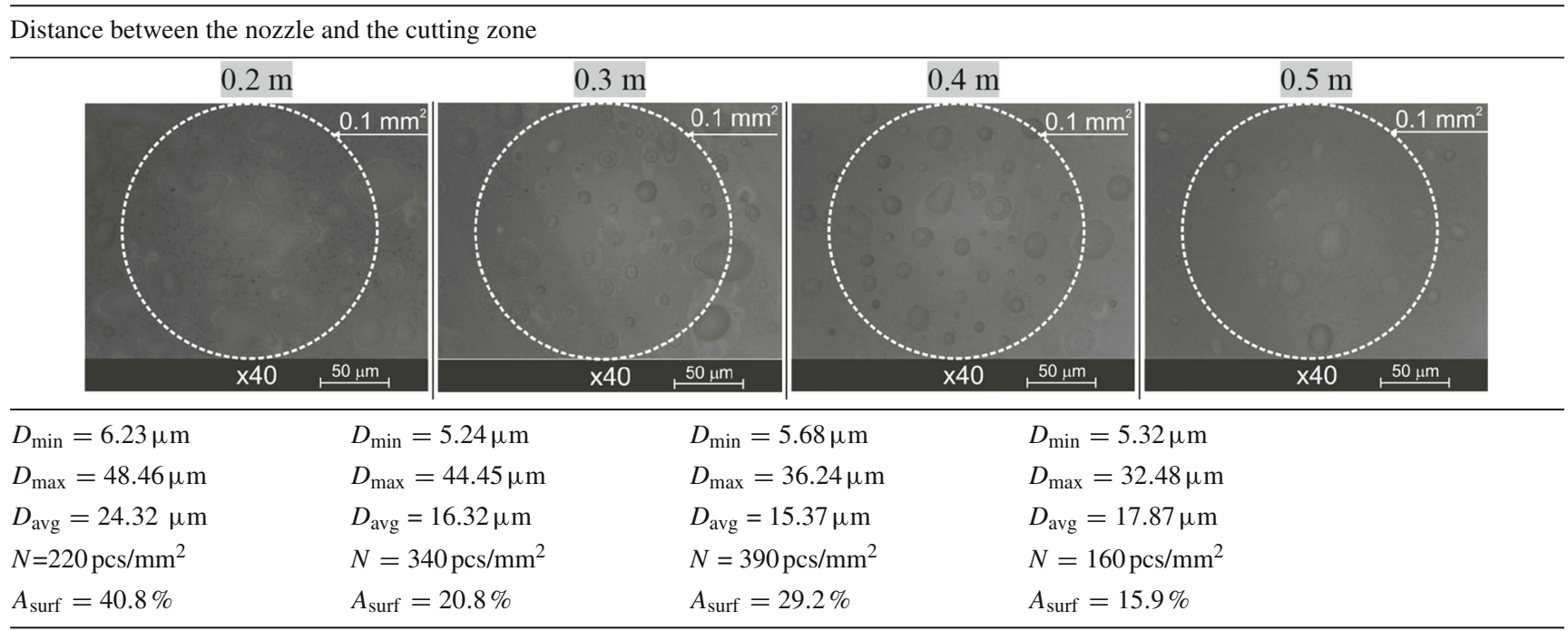

By transforming the formula, we obtain the drop heating time:

$t_{1}=\frac{2}{3} \cdot \frac{c_{p} d}{\alpha m^{2}}$
The drop diameter being known, it has been found that a drop of liquid bumping against a hard body is deformed so that the diameter of the trace of contact between the drop and the body surface is [21]:

where: $m=D / d$-drop deformation factor. 
$D=2\left[\frac{3 V_{\text {droplet }}}{4 \pi}\right]^{1 / 3}$,

where: $V_{\text {droplet }}$-drop volume in air.

For the process of a drop vaporization, the equation of the thermal balance is as follows [20]:

$\frac{\pi D^{2}}{4} \alpha\left(\Theta_{s}-\Theta_{n}\right) t_{2} \frac{\pi d^{3}}{6} \rho r$,

where: $r$-specific heat of water evaporation; $\Theta_{s}$ - heated surface temperature determined based on the analysis of the

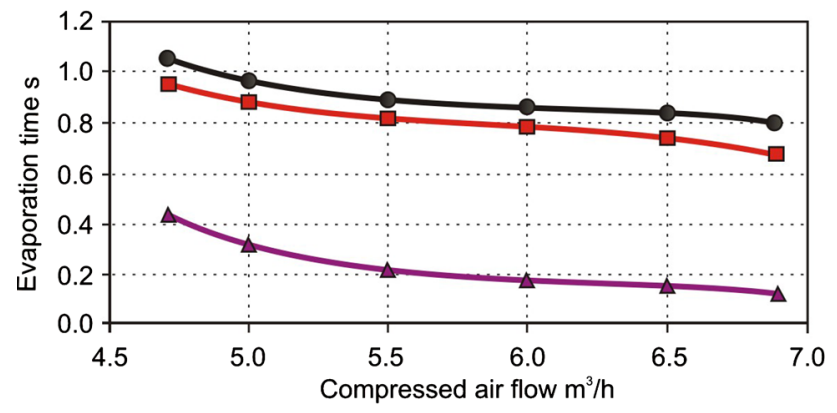

$\triangle-E=1.8 \mathrm{~g} / \mathrm{min}-\square-E=2.6 \mathrm{~g} / \mathrm{min}-0-E=3.6 \mathrm{~g} / \mathrm{min}$

Fig. 2 Time of vaporization of all the drops falling on the heated surface in $1 \mathrm{~s}$ depending on the flows of air and emulsion for $L=0.4 \mathrm{~m}$ temperature of the "chip-cutting wedge-machined material" contact zone and temperature of the machined material and chip areas nearest to that zone [22]; $\rho$-water density.

Hence

$t_{2}=\frac{2}{3} \cdot \frac{\rho r d}{\alpha m^{2}\left(\Theta_{s}-\Theta_{n}\right)}$

The total time of a single-drop vaporization is:

$t_{w}=t_{1}+t_{2}$

Figure 2 shows the condition of vaporization of all the drops on the heated surface in the time of one second depending on the flows of emulsion and air. With the increase in air flow, the volume of drops falling into the cutting zone decreases, which reduces the total time of their vaporization. Only in the case of high flow of emulsion and low air flow, emulsion droplets can remain on the surface being machined (the total vaporization time exceeds $1 \mathrm{~s}$ ).

Judiciously selected conditions of emulsion mist formation $\left(E<3.6 \mathrm{~g} / \mathrm{min}\right.$ and $\left.P>5.0 \mathrm{~m}^{3} / \mathrm{h}\right)$ result in that all the drops falling on the heated surface in unit 1s evaporate from that surface (Fig. 2). In the case of large drop diameters (more than $15 \mu \mathrm{m}$ ) and emulsion flow values more than $3.5 \mathrm{~g} / \mathrm{min}$, some volume of droplets is not evaporated (Fig. 3). This means that all the chemical compounds or other active sub-

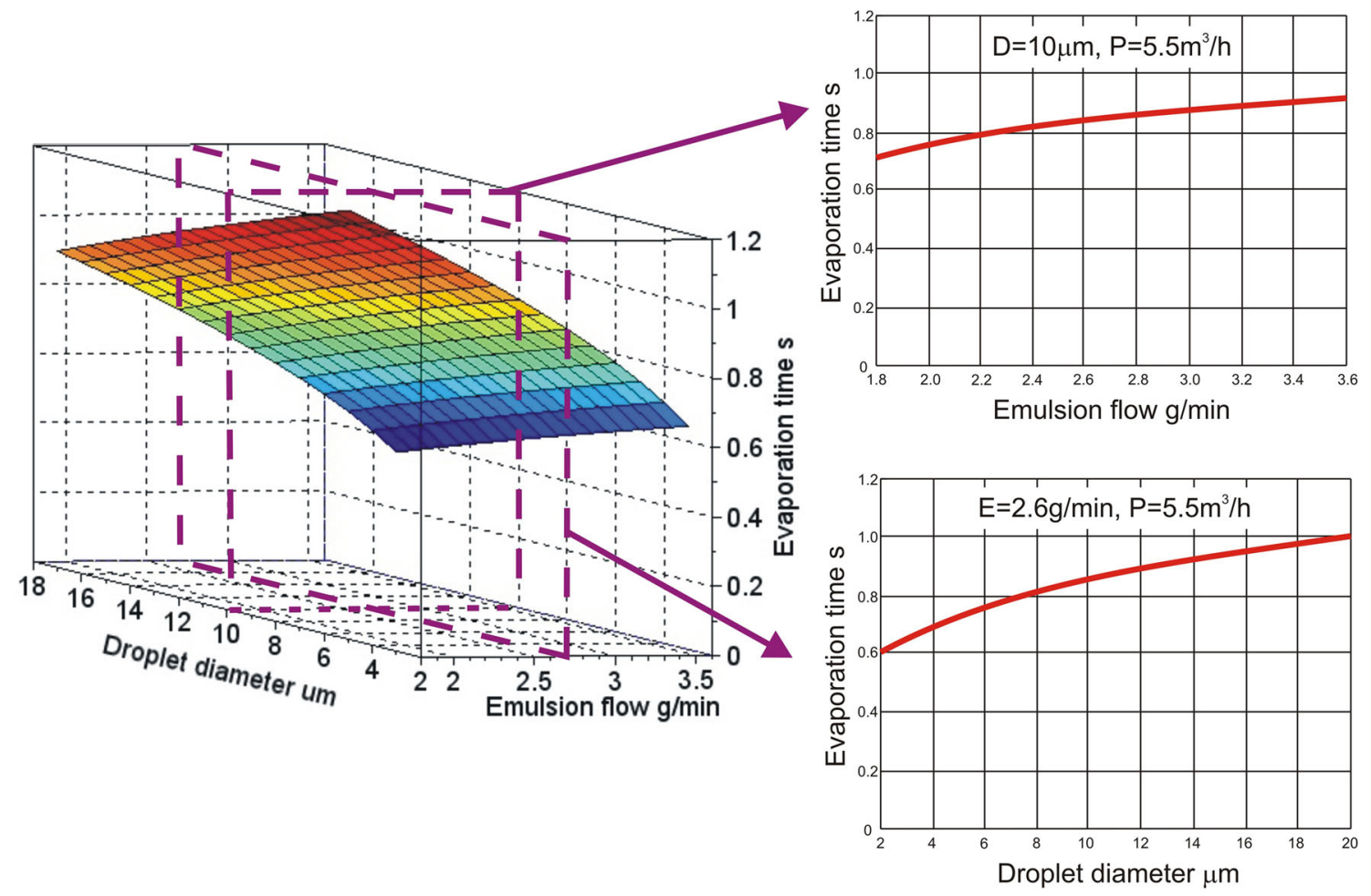

Fig. 3 Time of vaporization of drops falling on the heated surface in one second depending on the drop diameter and emulsion flow with the air flow of $P=4.7-6.9 \mathrm{~m}^{3} / \mathrm{h}$ 
stances contained in the emulsion mist remain on the surfaces of the element, chip and cutting wedge and at their contact surfaces. It is proved by the analysis of the changes in the cutting wedge rake face with the use of a scanning microscope; this analysis has been shown below. Figures 2 and 3 presents modelled experimental data.

\subsection{Microstructure and Composition Analysis of the Cutting Wedge Rake Face}

A scanning microscope has been utilized to analyse the rake faces of a P25 sintered carbide insert: prior to turning, i.e. in the input condition (Fig. 4), after turning with MQCL cooling beyond the boundary of the chip contact with the rake face (Fig. 5), the rake face which has directly participated in the

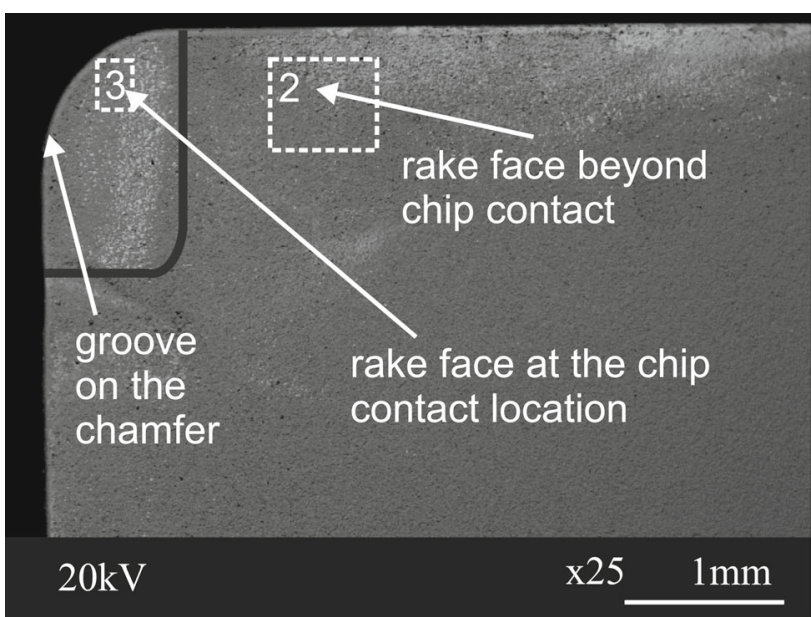

Fig. 4 Analysis of the content of elements on the rake face of a P25 sintered carbide plate in the input condition-prior to the process of turning; energetic spectrum in place 1 (magnification $\times 100$, SE detector) turning process, i.e. the area of the chip and wedge contact zone (Fig. 5).

Figure 5 shows an example of an insert surface in the initial condition. Prior to machining test, SEM analysis has shown a typical chemical composition of P25 sintered carbide.

After the process of machining, traces of the elements contained in the active medium of the emulsion mist have been found on the rake face of the cutting wedge (Fig. 6).

In the chip contact zone on the rake face, an increased percentage of fluorine, over $23.9 \%$, has been found (Fig. 7), while beyond the place of contact, the quantity of fluorine is as low as about $7.5 \%$ (Fig. 6) and there is no fluorine at all on the plate in its initial state. When applying MQCL, significant variations in the energy flow in the contact zone [23] result in acceleration of chemical reactions and, consequently, more compounds of type EP and AW (fluorates and sulphates) remain on the contact surfaces.

The increase in percentage content of fluorine on the cutting tool point is a result of higher temperature in the contact zone on the rake face. This results in a much faster evaporation of the emulsion droplets than in the other zones. Chemically active compounds included in Methanol-M interact with the wedge material in the contact zone and form new compounds with the components of the cemented carbide. In the remaining zones, lower cutting temperatures are observed and therefore the process proceeds more slowly.

For the cutting speed of $250 \mathrm{~m} / \mathrm{min}$, built-up edge and wear can be observed on the rake face. According to Krolczyk et al. [24], growth of the cutting speed increases wear in the cutting wedge. Kummel et al [25] have been investigating AISI 1045 steel in normalized state and have found that the surface quality was increasing with the increase in cutting speed and reduction in built-up edge height. They have performed their tests for the cutting speed of 50 to $150 \mathrm{~m} / \mathrm{min}$. They have shown that the built-up edge height and the area

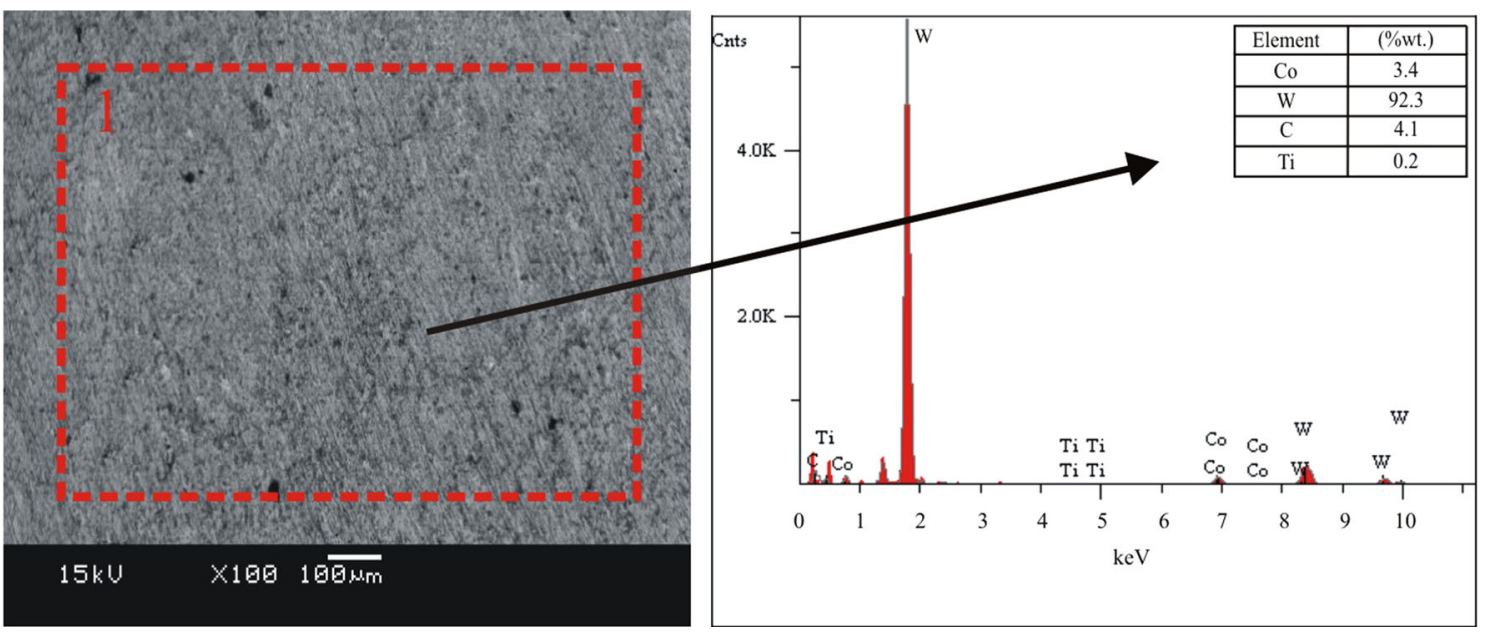

Fig. 5 Rake face of the cutting wedge subjected to scanning inspection after the process of turning under MQCL conditions 


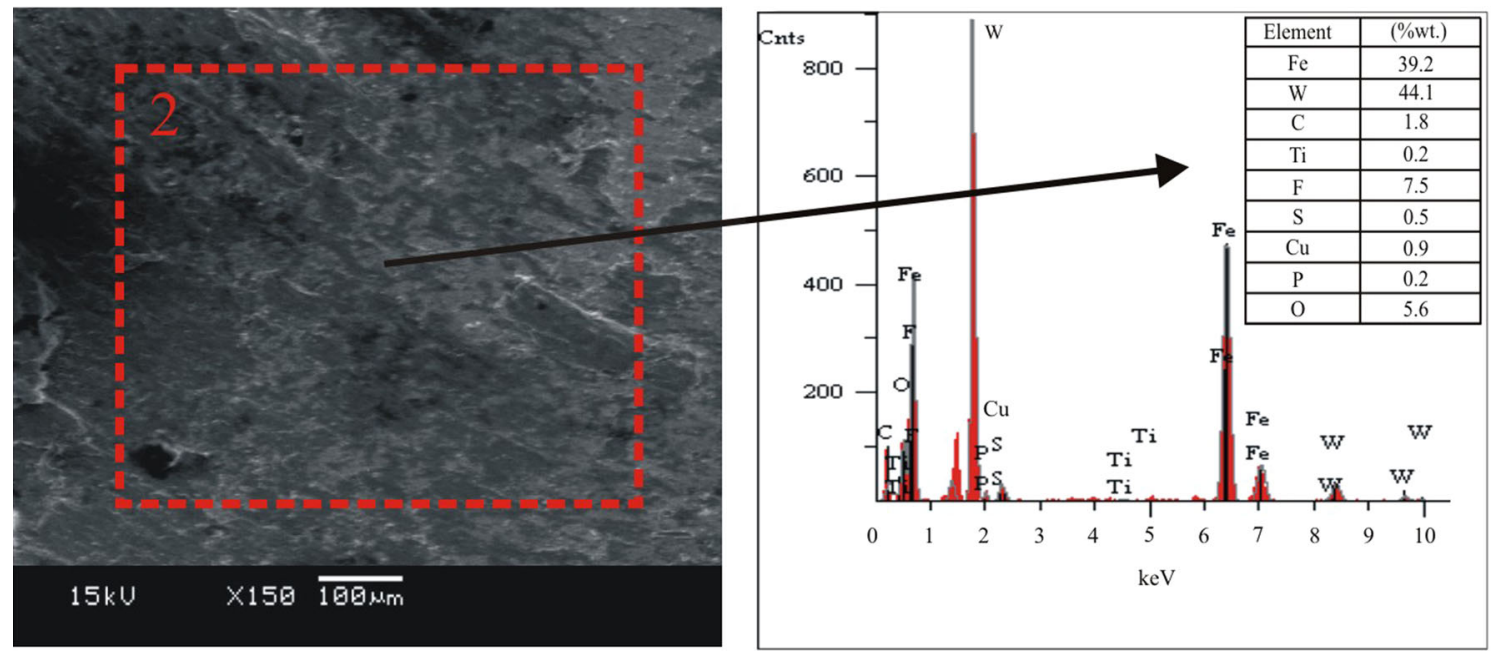

Fig. 6 Analysis of the content of elements on the rake face of a P25 sintered carbide plate after turning AISI 1045 steel beyond the chip contact under MQCL conditions; energetic spectrum in place 2 (magnification $\times 150$, SE detector)

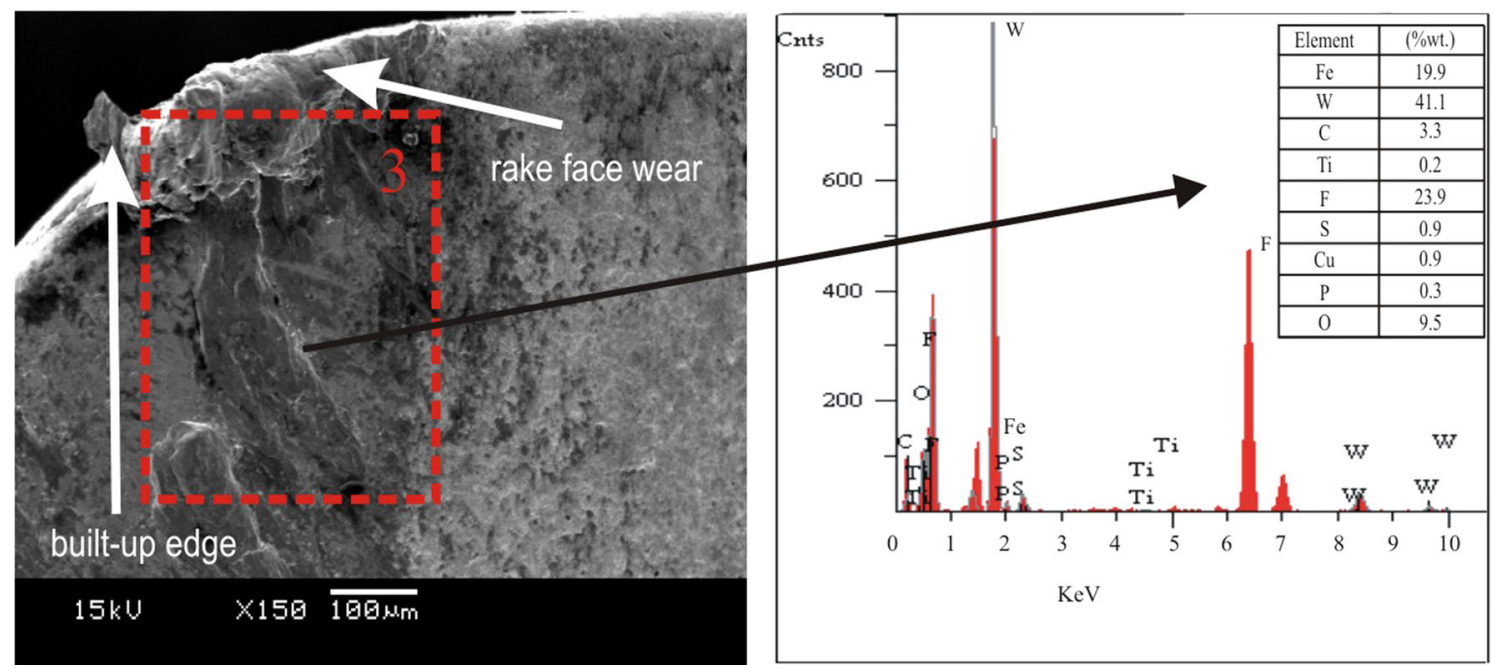

Fig. 7 Analysis of the content of elements on the rake face of a P25 sintered carbide plate in the zone of chip contact with the rake face after turning AISI 1045 steel under MQCL conditions; energetic spectrum in place 3 (magnification $\times 150$, SE detector)

covered by the built-up edge decrease with the increase in the cutting speed.

\section{Conclusions}

Based on the analysis of heat flow in the cutting zone and scanning inspections of the cutting wedge, the following conclusions have been determined:

I. The smallest diameter of the droplets was observed for the distance from the nozzle to the interface cutting tool-workpiece material is equal to $0.4 \mathrm{~m}$. The distance $L$ below $0.3 \mathrm{~m}$ results in a total of droplets on the surface, while above $0.4 \mathrm{~m}$ decrease in the number of droplets, thus reducing the total area of wettability.
II. Under the MQCL conditions, one can select such conditions of mist formation $(E<3.6 \mathrm{~g} / \mathrm{min}$ and $P>$ $5.0 \mathrm{~m}^{3} / \mathrm{h}$ ) in which all the drops falling on the heated surface in a second will predominantly evaporate from that surface.

III. The time of the drops vaporization is reduced proportionally to the reduction in single-drop diameter. This ensures the possibility of regulating the process through adjusting the mist formation conditions.

IV. After the evaporation of the drops, all the chemical compounds or other active substances contained in the emulsion mist remain on the surface of the machined material, the chips and the cutting edge in the intensified state. In the contact zone, the concentration of those compounds is three times that on the surfaces 
beyond the contacts. This is due to the formation of a boundary layer favourably influencing the conditions of machining.

Open Access This article is distributed under the terms of the Creative Commons Attribution 4.0 International License (http://creativecommons. org/licenses/by/4.0/), which permits unrestricted use, distribution, and reproduction in any medium, provided you give appropriate credit to the original author(s) and the source, provide a link to the Creative Commons license, and indicate if changes were made.

\section{References}

1. Byrne, G.; Dornfeld, D.; Denkena, B.: Advancing cutting technology. Ann. CIRP 52, 483-507 (2003)

2. Narutaki, N.; Yamane, Y.; Tashima, S.; Kuroki, H.: A new advanced ceramic for dry machining. Ann. CIRP 46, 43-48 (1997)

3. Klocke, F.; Eisenblaetter, G.: Machinability investigation of the drilling process using minimal cooling lubrication techniques. Prod. Eng. 4, 19-24 (1997)

4. Lawal, S.A.; Choudhury, I.A.; Nukman, Y.: A critical assessment of lubrication techniques in machining processes: a case for minimum quantity lubrication using vegetable oil-based lubricant. J. Clean. Prod. 41, 210-221 (2013)

5. Hadad, M.; Sadeghi, B.: Minimum quantity lubrication-MQL turning of AISI 4140 steel alloy. J. Clean. Prod. 54, 332-343 (2013)

6. Fratila, D.F.; Caizar, C.: Assessment of cooling effect and surface quality to face milling of $\mathrm{AlMg}_{3}$ using several cooling lubrication methods. Mater. Manuf. Process. 27, 291-296 (2012)

7. Aoyama, T.; Kakinuma, Y.; Yamashita, M.; Aoki, M.: Development of a new lean lubrication system for near dry machining process. CIRP Ann. Manuf. Technol. 57, 125-128 (2008)

8. Jun, M.B.G.; Joshi, S.S.; DeVor, R.E.; Kapoor, S.G.: An experimental evaluation of an atomization-based cutting fluid application system for micromachining. J. Manuf. Sci. Eng. 130, 03111810311188 (2008)

9. Klocke F.; Gerschwiler K.: Minimalmengenschmierungsysteme, Medien, Einsatzbeispiele und ökonomische Aspekte der Trockenbearbeitung, Trockenbearbeitung von Metallen, Proc. of the VDI-Seminar, Stuttgart, Mar. vol. 18, pp. 2.1-2.20 (2003)

10. Gaitonde, V.N.; Karnik, S.R.; Paolo Davim, J.: Selection of optimal MQL and cutting conditions for enhancing machinability in turning of brass. J. Mater. Process. Technol. 204, 459-464 (2008)

11. Simpson, A.T.; Stear, M.; Groves, J.A.; Piney, M.; Bradley, S.D.; Stagg, S.; Crook, B.: Occupational exposure to metalworking fluid mist and sump fluid contaminants. Ann. Occup. Hyg. 47, 17$30(2003)$
12. Aoyama, T.: Development of a mixture supply system for machining with minimal quantity lubrication. CIRP Ann. Manuf. Technol. 51, 289-292 (2002)

13. Sarikaya, M.; Gullu, A.: Taguchi design and response surface methodology based analysis of machining parameters in CNC turning under MQL. J. Clean. Prod. 65, 604-616 (2014)

14. Sanchez, J.A.; Pombo, I.; Alberdi, R.; Izquierdo, B.; Ortega, N.; Plaza, S.; Martinez-Toledano, J.: Machining evaluation of a hybrid MQL- $\mathrm{CO}_{2}$ grinding technology. J. Clean. Prod. 18, 18401849 (2010)

15. Krolczyk, G.M.; Legutko, S.: Experimental analysis by measurement of surface roughness variations in turning process of duplex stainless steel. Metrol. Meas. Syst. XXI, 759-770 (2014)

16. Krolczyk, G.; Legutko, S.; Nieslony, P.; Gajek, M.: Study of the surface integrity microhardness of austenitic stainless steel after turning. Tehnički Vjesn. Techn. Gaz. 21, 1307-1311 (2014)

17. Zhang, S.; Li, J.F.; Wang, Y.W.: Tool life and cutting forces in end milling Inconel 718 under dry and minimum quantity cooling lubrication cutting conditions. J. Clean. Prod. 32, 81-87 (2012)

18. Adler, D.P.; W-S. Hii, W.; Michalek, D.J.; Sutherland, J.W.: Examining the role of gutting fluids and efforts to address associated environmental/health concerns. Mach. Sci. Technol. 10, 23-58 (2006)

19. Li, C.H.; Hou, Y.L.; Xiu, S.C.; Cai, G.Q.: Application of lubrication theory to near-dry-green grinding-feasibility analysis. Adv. Mater. Res. 44(-46), 135-142 (2008)

20. Khan, A. A.: Role of heat transfer on process characteristics during electrical discharge machining. Developments in Heat Transfer. pp. 417-436 (2011)

21. Park, K.H.; Olortegui-Yume, J.; Yoon, M.C.; Kwon, P.: A study on droplets and their distribution for minimum quantity lubrication. Int. J. Machine Tools Manuf. 50, 824-833 (2010)

22. Yashcheritsyn, P.I.; Feldshtein, E.E.; Kutser, V.M.; Sharaf, A.H.; Diallo, U.: Modeling and study of thermal processes in the technological machining system using finite element method. Proceedings of the National Academy of Sciences of Belarus, Series of PhysicTechnical Sciences. vol. 1, pp. 112-117 (1991) (in Russian).

23. Feldshtein, E.; Maruda, R.: Analysis of the cutting force and heat sink changes when turning of C45 steel in MQCL conditions on the basis of computer modeling. Int. J. Appl. Mech. Eng. 15, 10371045 (2010)

24. Krolczyk, G.M.; Nieslony, P.; Legutko, S.: Determination of tool life and research wear during duplex stainless steel turning. Arch. Civil Mech. Eng. 15, 347-354 (2015)

25. Kummel, J.; Gibmeier, J.; Muller, E.; Schneider, R.; Schulze, V.; Wanner, A.: Detailed analysis of microstructure of intentionally formed built-up edges for improving wear behaviour in dry metal cutting process of steel. Wear 311, 21-30 (2014) 